\title{
Comparaison des variants $A$ et $C$ de la caséine $\beta$ des laits de vaches Tarentaises en modèle fromager de type beaufort. I. Aptitudes fromagères et rendements en frais
}

\author{
A Delacroix-Buchet, C Marie * \\ INRA, Station de recherches laitières, 78352 Jouy-en-Josas, France
}

(Reçu le 27 avril 1994; accepté le 12 juillet 1994)

\begin{abstract}
Résumé - Le beaufort est un fromage d'appellation d'origine contrôlée fabriqué à partir du lait de vaches de Tarentaise $(65 \%)$ et d'Abondance (35\%). Dans ce type de fromage à pâte cuite pressée, les caractéristiques d'affinage dépendent, pour une part importante, de la protéolyse de la caséine $\beta(\beta-C n)$ par la plasmine. Les vaches de race Tarentaise possèdent avec une fréquence élevée (17\%) le variant $C$ de la $\beta-C n$, variant quasi absent dans la plupart des autres races de vaches laitières. Ce variant a été comparé en fabrication expérimentale de minifromages de type beaufort au variant $A$ de la $\beta$-Cn très fréquent. Les laits possédant le variant $C$ de la $\beta$-Cn ont des micelles de caséine de grand diamètre $(+57 \%)$, peu calcifiées $(-14 \%)$ par rapport aux laits témoins $\beta-C n$ A, d'où une aptitude à la coagulation par la présure atypique (agrégation de sous-unités micellaires), se traduisant par l'obtention d'un caillé moins ferme $(-33 \%)$, avec des pertes de matière grasse importantes dans le lactosérum de fromagerie et des rendements fromagers moindres $(-12 \%$ et $-15 \%$ respectivement pour les rendements brut et corrigé de l'extrait sec des fromages frais).
\end{abstract}

fromage / beaufort / caséine $\beta$ / variant génétique / Tarentaise / micelle / coagulation à la présure / rendement fromager

Summary - $\beta$-Casein $C$ and Beaufort type cheese production. Beaufort cheese is a fromage d'Appellation d'Origine made with milk from Tarentaise (65\%) and Abondance (35\%) cows. In this type of cooked curd cheeses, the ripening characteristics depend primarily on the proteolysis of $\beta$ casein ( $\beta$-Cn) by plasmin. Tarentaise cows have a high frequency $(17 \%)$ of the $\beta$-Cn $C$ variant which is nearly absent from most breeds of dairy cows. This variant was compared to the highly frequent $\beta$ Cn A variant in laboratory-scale production of small Beaufort-type cheeses. Compared to $\beta$-Cn A milk,

\footnotetext{
* Stagiaire de DEA, ENSA, Rennes, France. Adresse actuelle : INRA Auzeville, station d'amélioration génétique des animaux, BP 27, 31326 Castanet-Tolosan Cedex, France.
} 
$\beta$-Cn C milk has casein micelles with a bigger diameter ( $+57 \%)$ and lower calcium content $(-14 \%)$ and thus a non-typical behaviour during rennet coagulation leading to soft curd (firmness $-33 \%$ ), accompanied by a great fat loss in the whey and smaller cheese yield (actual $-12 \%$ and adjusted $-15 \%$ ).

cheese / Beaufort / $\beta$-casein / genetic variant / Tarentaise / micelle / rennet coagulation / cheese yield

\section{INTRODUCTION}

Le fromage de Beaufort est un fromage d'appellation d'origine, à pâte cuite pressée et à croûte morgée, fabriqué dans 4 régions naturelles des Alpes (le val-d'Arly, le Beaufortin, la Tarentaise et la Maurienne). Sa production est régie par le décret du 29 décembre 1986 qui précise, entre autres, les races du troupeau laitier de la zone de Beaufort. Ce troupeau est constitué pour $64 \%$ de vaches de Tarentaise et pour $30 \%$ de vaches d'Abondance. La race de Tarentaise se caractérise par une fréquence élevée de variants rares des caséines (Grosclaude, 1988 ; Nuyts-Petit, 1991). Nuyts-Petit (1991) rapporte une fréquence de l'allèle $D$ de la caséine $\alpha_{\mathrm{s} 2}\left(\alpha_{\mathrm{s} 2^{-}}\right.$ Cn) de $7 \%$, de l'allèle $C$ de la caséine $\beta$ ( $\beta$ $\mathrm{Cn}$ ) de $17 \%$ et de l'allèle $C$ de la caséine $\kappa$ $(k-\mathrm{Cn})$ de $9 \%$ à partir de 328 vaches typées en 1989. La fréquence de la $\beta-C n C$ a augmenté entre 1967 et 1989, passant de 11 à $17 \%$. Les laits individuels de vaches tarentaises possédant l'haplotype $\alpha_{\mathrm{s} 1}-\mathrm{Cn} \mathrm{A}, \alpha_{\mathrm{s} 2}-$ $\mathrm{Cn} A, \beta-\mathrm{Cn} C$ et $\mathrm{k}$ - $\mathrm{Cn} A$ se distinguent très nettement des autres laits de vaches tarentaises par leur composition physico-chimique et leurs propriétés lactodynamiques mesurées au formagraph. Leur structure micellaire particulière (fort diamètre micellaire, taux élevé de $\alpha_{\mathrm{s}}-\mathrm{Cn}$ et faible de $\mathrm{k}$-Cn) modifie l'aptitude à la coagulation par la présure et se traduit par un caillé mou, bien que le temps de gélification soit relativement court. L'incidence du variant $\beta-C n C$ n'a pas été évaluée en fabrication fromagère.

Le variant $\beta$-Cn $C$ présente par rapport aux variants $A\left(A^{1}\right.$ ou $A^{2}$ ) fréquents en race de Tarentaise, une substitution du résidu Glu 37 par un résidu Lys ce qui provoque la non-phosphorylation du résidu Ser 35 (Grosclaude, 1988). Outre une vraisemblable modification de la structure spatiale de la molécule, cette nouvelle forme fait apparaître un site potentiel supplémentaire de coupure de la $\beta$-Cn par la plasmine (Weinstein et Doolittle, 1972) étudié in vitro par Papoff et al (1994). Or, cette enzyme endogène du lait joue un rôle important dans l'affinage des fromages à pâte cuite (Casey et al, 1986 ; Collin et al, 1987 ; Farkye et Fox, 1990) car l'activité d'une autre protéase importante, la chymosine est détruite lors du chauffage du caillé, en cuve de fabrication, à une température supérieure à $50^{\circ} \mathrm{C}$ (Matheson, 1981 ; Delacroix-Buchet et Fournier, 1992).

L'originalité de structure du variant $\beta-C n$ $\mathrm{C}$, son incidence sur le comportement du lait vis-à-vis de la présure et sur la dégradation de la $\beta$-Cn par la plasmine, méritaient l'étude de ce variant dans le cadre de fabrications de fromages à pâte cuite pressée type beaufort. II s'agissait de connaître l'effet de ce variant sur la protéolyse, la texture et la flaveur des produits affinés, sachant que les peptides participent aux caractéristiques de goût des fromages (Berdagué et Grappin, 1988; Olson, 1990; Visser, 1993). C'est l'objet du travail dont nous présenterons les résultats dans une série de 2 articles.

Pour mener à bien l'étude, des minifromages de type beaufort ont été fabriqués à partir de laits individuels de vaches tarentaises possédant l'haplotype $\alpha_{s 1}$ - Cn B, $\beta$ $\mathrm{Cn} \mathrm{C}, \mathrm{k}$ - $\mathrm{Cn} \mathrm{A}$ el comparés à des minifromages témoins fabriqués avec des laits individuels de vaches de même race pos- 
sédant I'haplotype $\alpha_{s 1}-C n B, \beta-C n A$ ( $A^{1}$ ou $\left.A^{2}\right), \kappa-C n A$ fréquent en race de Tarentaise, ne différant que par l'allèle de la $\beta-C n$. Dans ce premier article, nous décrirons le dispositif expérimental et nous analyserons les caractéristiques des laits individuels mis en fabrication, le déroulement des fabrications, la composition des fromages et les rendements en fromages frais obtenus. Dans le second article, nous présenterons les résultats concernant la protéolyse et les caractéristiques sensorielles (goût et texture) des fromages.

\section{MATÉRIEL ET MÉTHODES}

L'objectif des essais étant de caractériser au mieux les particularités du variant $C$ rare de la $\beta$ Cn par rapport à un témoin fréquent dans la plupart des races bovines (le variant $A$, englobant ici indifféremment le variant $A^{\top}$ et le variant $A^{2}$ ), nous avons d'abord caractérisé les laits individuels destinés aux fabrications fromagères, sur les plans microbiologique, physico-chimique et théologique puis, nous avons suivi le comportement en fabrication fromagère et comparé les rendements fromagers obtenus avec les laits des 2 génotypes.

\section{Protocole expérimental}

\section{Choix des animaux}

À l'aide des typages électrophorétiques réalisés en 1988 et 1989 sur des vaches tarentaises de Savoie et du domaine expérimental INRA de Marcenat (Nuyts-Petit, 1991), nous avons choisi de prélever le lait d'animaux homozygotes pour la $\beta-C n$, bien que le variant $C$ de la $\beta$ - $C$ n soit rare, afin d'exacerber les différences existant entre les deux génotypes à comparer.

Pour chaque série de fabrications, un lait témoin $\beta-C n$ AA est comparé à des laits $\beta-C n$ $\mathrm{CC}$. Le reste du génotype demeure identique pour tous les animaux, afin que les variants des autres caséines n'interfèrent pas avec l'action du variant $\mathrm{C}$ de la $\beta-\mathrm{Cn}$.
Sur 328 animaux typés, 9 vaches tarentaises homozygotes $\beta$-Cn $C$ recensées possèdent toutes le même haplotype: $\alpha_{s 1}-C n B B, \alpha_{s 2}-C n A A, \beta$ $\mathrm{Cn} C \mathrm{C}$ et $\mathrm{x}-\mathrm{Cn} \mathrm{AA}$. Les animaux témoins choisis pour la comparaison présentent l'haplotype voisin avec pour seule modification la $\beta-C n$.

Sur les 9 animaux $\beta$-Cn C typés en 1989, nous avons retenu 5 individus ( 4 en Savoie et 1 dans le Massif Central) répondant aux critères imposés par l'expérimentation: ils ne consomment pas d'ensilage, sont à un stade de lactation moyen et sont dans un bon état sanitaire (absence de mammite).

Au total, 15 minifabrications ont été réalisées en mars et en avril 1991 à partir des laits de 5 vaches $\beta$-Cn $C$ et de 4 vaches $\beta$-Cn $A$ individuels (tableau I). À l'origine, le protocole prévoyait de fabriquer un plus grand nombre de fromages avec du lait de vaches toutes différentes. Le nombre restreint d'animaux disponibles nous a contraints à prélever plusieurs fois certaines vaches pour avoir un nombre suffisant de répétitions.

\section{Collecte, échantillonnage et transport des laits}

Les laits individuels de la traite du matin (6 à 8 ।) provenant d'exploitations agricoles aussi proches que possible ont été conditionnés sur place en répartissant chaque traite dans un récipient refroidi par immersion dans un bac d'eau glacée et placé dans une caisse isotherme remplie de pains de glycol réfrigérant. Ce lait était destiné à la réalisation de minifabrications de fromages à pâte cuite pressée à la laiterie expérimentale de la station de recherches laitières de I'INRA de Jouy-en-Josas. Son refroidissement permettait de limiter le développement microbien au cours du transport. Un échantillon de $200 \mathrm{ml}$ de lait, additionné d'un conservateur (azothydrate de sodium à $40 \mathrm{mg} / \mathrm{l}$ de lait) pour inhiber tout développement bactérien, destiné aux analyses physicochimiques a été acheminé à température ambiante. Le refroidissement de cet échantillon aurait modifié les équilibres minéraux du lait et faussé les mesures ultérieures des dimensions des micelles de caséines ou de comportement du lait vis-à-vis de la présure (Ichilczyk-Leone et al, 1981). Enfin, un deuxième échantillon de $20 \mathrm{ml}$ de lait, additionné de dichromate de potassium, destiné au comptage des leucocytes a été envoyé au Laboratoire Interprofessionnel Départemental d'Analyses du Lait (LIDAL) d'Annecy. 
Tableau I. Planning des minifabrications fromagères.

Planning of cheese miniprocessing.

\begin{tabular}{|c|c|c|c|c|c|c|c|c|c|c|c|}
\hline $\begin{array}{l}\text { Date de } \\
\text { fabrication }\end{array}$ & Nom vache & $\begin{array}{c}\hat{A} g e \\
\text { (année) }\end{array}$ & Date de vêlage & No lact & $\alpha_{s 1}$ & $\alpha_{s 2}$ & $\underset{\beta}{\text { Génotype }}$ & $\kappa$ & $\beta / g$ & $\begin{array}{c}\text { Leucocytes } \\
\left(10^{3} / \mathrm{ml}\right)\end{array}$ & $\begin{array}{c}\text { Flore totale } \\
\left(10^{3} / \mathrm{ml}\right)\end{array}$ \\
\hline $5 / 03 / 91$ & $\begin{array}{l}\text { Virgule } \\
\text { Vermeille } \\
\text { Biquette }\end{array}$ & $\begin{array}{l}7 \\
7 \\
5\end{array}$ & $\begin{array}{r}2 / 11 / 90 \\
18 / 12 / 90 \\
12 / 11 / 90\end{array}$ & $\begin{array}{l}4 \\
5 \\
3\end{array}$ & $\begin{array}{l}\text { BB } \\
\text { BB } \\
\text { BB }\end{array}$ & $\begin{array}{l}\text { AA } \\
\text { AA } \\
\text { AA }\end{array}$ & $\begin{array}{c}C C \\
C C \\
A^{2} A^{2}\end{array}$ & $\begin{array}{l}\text { AA } \\
\text { AA } \\
\text { AA }\end{array}$ & $\begin{array}{l}A B \\
A B \\
A B\end{array}$ & $\begin{array}{l}98 \\
43 \\
98\end{array}$ & $\begin{array}{r}64 \\
500 \\
140\end{array}$ \\
\hline $12 / 03 / 91$ & $\begin{array}{l}\text { Urgente } \\
\text { Roulette } \\
\text { Virgule }\end{array}$ & $\begin{array}{r}8 \\
11 \\
7\end{array}$ & $\begin{array}{r}17 / 01 / 91 \\
18 / 01 / 91 \\
2 / 11 / 90\end{array}$ & $\begin{array}{l}6 \\
8 \\
4\end{array}$ & $\begin{array}{l}\text { BB } \\
\text { BB } \\
\text { BB }\end{array}$ & $\begin{array}{l}\text { AA } \\
\text { AA } \\
\text { AA }\end{array}$ & $\begin{array}{c}C C \\
A^{1} A^{2} \\
C C\end{array}$ & $\begin{array}{l}\text { AA } \\
\text { AA } \\
\text { AA }\end{array}$ & $\begin{array}{l}B B \\
B B \\
A B\end{array}$ & $\begin{array}{l}311 \\
108 \\
107\end{array}$ & $\begin{array}{l}63 \\
43 \\
21\end{array}$ \\
\hline $13 / 03 / 91$ & $\begin{array}{l}\text { Havel } \\
\text { Hate }\end{array}$ & $\begin{array}{l}4 \\
4\end{array}$ & $\begin{array}{l}11 / 01 / 91 \\
28 / 12 / 91\end{array}$ & $\begin{array}{l}2 \\
2\end{array}$ & $\begin{array}{l}\text { BB } \\
\text { BB }\end{array}$ & $\begin{array}{l}A A \\
A A\end{array}$ & $\begin{array}{c}C C \\
A^{1} A^{1}\end{array}$ & $\begin{array}{l}A A \\
A A\end{array}$ & $\begin{array}{l}A B \\
A B\end{array}$ & $\begin{array}{l}25 \\
21\end{array}$ & $\begin{array}{r}8 \\
34\end{array}$ \\
\hline $2 / 04 / 91$ & $\begin{array}{c}\text { Alerte } \\
\text { Vermeille }\end{array}$ & $\begin{array}{l}6 \\
7\end{array}$ & $\begin{array}{l}15 / 11 / 90 \\
18 / 12 / 90\end{array}$ & $\begin{array}{l}3 \\
5\end{array}$ & $\begin{array}{l}\text { BB } \\
\text { BB }\end{array}$ & $\begin{array}{l}A A \\
A A\end{array}$ & $\begin{array}{c}A^{1} A^{2} \\
C C\end{array}$ & $\begin{array}{l}A A \\
A A\end{array}$ & $\begin{array}{l}A B \\
A B\end{array}$ & $\begin{array}{l}298 \\
296\end{array}$ & $\begin{array}{r}3 \\
270\end{array}$ \\
\hline $9 / 04 / 91$ & $\begin{array}{l}\text { Urgente } \\
\text { Roulette }\end{array}$ & $\begin{array}{r}8 \\
11\end{array}$ & $\begin{array}{l}17 / 01 / 91 \\
18 / 01 / 91\end{array}$ & $\begin{array}{l}6 \\
8\end{array}$ & $\begin{array}{l}\text { BB } \\
\text { BB }\end{array}$ & $\begin{array}{l}A A \\
A A\end{array}$ & $\begin{array}{c}C C \\
A^{1} A^{2}\end{array}$ & $\begin{array}{l}\text { AA } \\
\text { AA }\end{array}$ & $\begin{array}{l}\text { BB } \\
\text { BB }\end{array}$ & $\begin{array}{r}29 \\
400\end{array}$ & $\begin{array}{l}18 \\
22\end{array}$ \\
\hline $23 / 04 / 91$ & $\begin{array}{l}\text { Bordeaux } \\
\text { Alerte } \\
\text { Vermeille }\end{array}$ & $\begin{array}{l}5 \\
6 \\
7\end{array}$ & $\begin{array}{l}15 / 02 / 91 \\
15 / 11 / 90 \\
18 / 12 / 90\end{array}$ & $\begin{array}{l}3 \\
3 \\
5\end{array}$ & $\begin{array}{l}\text { BB } \\
\text { BB } \\
\text { BB }\end{array}$ & $\begin{array}{l}A A \\
A A \\
A A\end{array}$ & $\begin{array}{c}C C \\
A^{1} A^{2} \\
C C\end{array}$ & $\begin{array}{l}\text { AA } \\
\text { AA } \\
\text { AA }\end{array}$ & $\begin{array}{l}A B \\
A B \\
A B\end{array}$ & $\begin{array}{r}70 \\
128 \\
34\end{array}$ & $\begin{array}{r}15 \\
4 \\
150\end{array}$ \\
\hline
\end{tabular}


Du fait de l'influence de la conservation du lait sur ses caractéristiques physico-chimiques et la mesure de son aptitude à la transformation fromagère, le délai entre la traite des animaux et l'arrivée des laits individuels à la laiterie expérimentale de Jouy-en-Josas n'a jamais excédé $7 \mathrm{~h}$. Dès l'arrivée au laboratoire, tous les échantillons de $200 \mathrm{ml}$ de lait ont été fractionnés en vue des diverses analyses physico-chimiques à venir.

\section{Fabrications fromagères}

À chaque fabrication, un lait témoin $\beta-C n A$ et 1 ou 2 laits essais $\beta-C n C$ ont simultanément été transformés pour pouvoir éliminer l'éventuel facteur de variation "date de fabrication" par un traitement statistique approprié. Des essais préliminaires, comprenant les aspects transport et conservation des laits, ont été réalisés sur des laits individuels de Savoie, afin de procéder à la mise au point du protocole expérimental.

\section{Caractéristiques des fabrications}

L'objectif était de fabriquer un fromage de Beaufort, ou tout du moins un fromage à pâte cuite pressée modélisant les phénomènes physicochimiques rencontrés en fabrication de fromage de Beaufort. Pour analyser l'impact des variants génétiques en transformation fromagère, nous avons cherché à nous affranchir d'autres paramètres de variation liés à l'animal. Ces biais, dus à la volonté d'étudier des laits individuels pour exacerber les différences entre les génotypes, ont été pris en compte et supprimés en modifiant le protocole de fabrication du beaufort (fig 1).

Ainsi, du fait du temps de transport des laits et des contraintes horaires du fromager, les laits n'ont été transformés que $24 \mathrm{~h}$ après la traite. Leur conservation est donc passée par une étape de refroidissement à $4^{\circ} \mathrm{C}$, ce qui est interdit en fabrication de fromage de Beaufort. L'existence de différences importantes de taux butyreux entre animaux pouvant masquer la variabilité liée au génotype, les laits ont été standardisés en matière grasse à $32 \mathrm{~g} /$, la veille de la fabrication et avant refroidissement, afin d'obtenir des fromages ayant un gras/sec d'environ $50 \%$. De plus, juste avant les fabrications, les laits ont été pasteurisés $\left(72^{\circ} \mathrm{C}\right.$, $18 \mathrm{~s})$ afin d'éliminer la flore indésirable. Ce chauffage du lait, interdit en Beaufort, ne détruit pas l'action enzymatique de la plasmine. II permet une sélection des agents microbiens de l'affinage

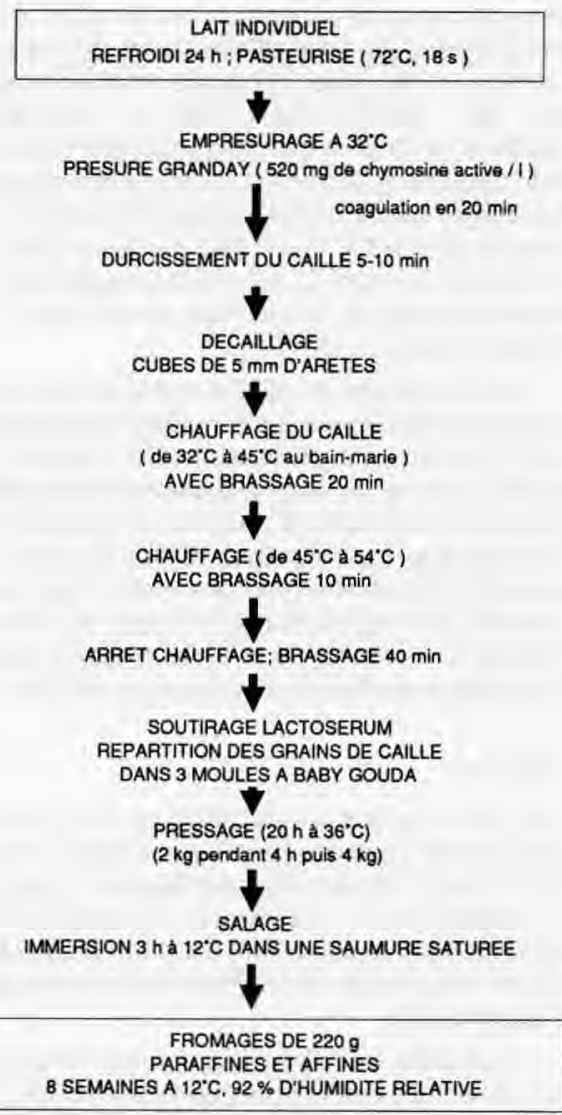

Fig 1. Protocole de minifabrication type beaufort. Diagram of Beaufort-type cheese miniprocessing.

(levains thermophiles ajoutés) sans qu'il y ait d'interférence avec la flore des laits.

Dès la sortie du pasteurisateur, une portion de $6 \mathrm{~kg}$ de lait pesés exactement était ensemencée à $33-34^{\circ} \mathrm{C}$, avec $0,15 \%$ de levain thermophile (Lactobacillus helveticus, souche CNRZ 303) dans des bacs de fabrication de $10 \mathrm{l}$. Comme en fabrication de fromage de Beaufort, le levain n'était composé que de lactobacilles (Chamba et al, 1994) et il n'y avait pas de maturation du lait. L'emprésurage était réalisé à $32^{\circ} \mathrm{C}$ avec un extrait de présure liquide (Granday, Beaune) à $520 \mathrm{mg}$ de chymosine active/ . La dose de présure était ajustée en fonction des résultats obtenus au Formagraph pour obtenir un temps de coagulation iden- 
tique pour tous les laits, d'environ 20 min et faciliter l'interprétation des différences de comportement des caillés. Après décaillage, 5-10 min après la prise, le chauffage des grains de caillé était réalisé à l'aide de 2 thermomix plongés dans le bain d'eau où était placée la cuve de fabrication. Le premier thermomix permettait une montée en température de $1^{\circ} \mathrm{C}$ toutes les 3 min jusqu'à $45^{\circ} \mathrm{C}$ et la mise en route du second thermomix accélérait la montée en température qui était de $1^{\circ} \mathrm{C}$ toutes les min, de 45 à $54^{\circ} \mathrm{C}$.

Après soutirage du caillé et moulage dans des moules à baby-Gouda, les fromages étaient pressés $20 \mathrm{~h}$ dans une pièce climatisée, maintenue à $36^{\circ} \mathrm{C}$, permettant le développement des lactobacilles et l'acidification corrrecte des fromages. Le fromage était d'abord pressé 15-20 min, avec un poids de $2 \mathrm{~kg}$, dans un peu de sérum chaud, puis retourné. Au deuxième retoumement, $4 \mathrm{~h}$ environ après le premier, la force de pressage était doublée par addition d'un autre poids de $2 \mathrm{~kg}$.

\section{Affinage}

Les minifromages ont été salés par immersion pendant $3 \mathrm{~h}$ dans une saumure saturée à $12^{\circ} \mathrm{C}$. On n'a pas procédé à l'emmorgeage de ces petits fromages. Ainsi, la plasmine et les lactobacilles thermophiles constituaient les principaux systèmes enzymatiques présents dans le modèle expérimental.

Pour éviter leur déshydratation, les fromages ont été enrobés dans de la paraffine et du fait de leur petite taille $(220 \mathrm{~g})$, ils ont été affinés 8 semaines et non 4 ou 6 mois comme des fromages de Beaufort, dans des caves à $12^{\circ} \mathrm{C}$ et $92 \%$ d'humidité relative.

\section{Méthodes}

Dès leur arrivée au laboratoire, les échantillons de lait, maintenus à température ambiante pendant leur transport, ont été fractionnés en 2 souséchantillons selon les analyses à effectuer. Le premier, constitué de lait entier frais était destiné à la mesure du $\mathrm{pH}$, au dosage de la matière grasse et de l'azote total ainsi qu'à la numération de la flore totale. Les analyses ont été effectuées sans délai. Le second, constitué du même lait, écrémé par centrifugation à $1500 \mathrm{~g}, 20$ min à $20^{\circ} \mathrm{C}$ et non réfrigéré, était réservé à l'étude de l'aptitude des laits à la coagulation par la pré. sure, à la mesure de la dimension des micelles de caséines et aux fractionnements chimiques azotés et minéraux. L'excédent de lait écrémé ainsi que les fractions minérales ou azotées préparées dès la réception des laits ont été congelés $\left(-20^{\circ} \mathrm{C}\right)$ pour être analysés ultérieurement.

Les fromages ont été analysés à $24 \mathrm{~h}$ au démoulage, après 2 semaines et 8 semaines d'affinage.

\section{Analyses microbiologiques et physiques}

- Flore totale des laits : numération par ensemencement sur milieu Plate Count agar (PCA) et incubation 3 jours à $30^{\circ} \mathrm{C}$ (norme FIL 49, 1970).

- Comptage cellulaire : méthode de Tolle décrite par Grappin et Jeunet (1971).

$-p H$ : mesure à l'aide d'un $\mathrm{pH}$-mètre équipé d'une électrode combinée à une aiguille Ingold Lot 406 pour le lait et le fromage. La mesure est effectuée par pénétration directe de l'électrode dans la pâte du fromage.

- Dimension des micelles de caséines : détermination à l'aide d'un analyseur de particules de marque Coulter modèle N4 (Coultronics France, Margency) par mesure du coefficient de diffusion et calcul d'après la loi de Stokes-Einstein (Lin et al, 1971). On place dans la cuve de mesure $20 \mu \mathrm{l}$ de lait et $3 \mathrm{ml}$ d'un ultrafiltrat d'un lait reconstitué à 10\% d'une poudre de lait low heat (INRA, Poligny) obtenus à l'aide d'un module Amicon 202 (Lexiton, États-Unis) équipé d'une membrane YM 10 et sous une pression d'azote de 3,5 bars. Parmi les nombreux paramètres fournis par l'appareil, 3 ont été retenus pour l'exploitation des résultats qui caractérisent correctement la distribution de taille des micelles. Ce sont (en $\mathrm{nm}$ ), le diamètre moyen des micelles de caséine $(\mathrm{DMO})$, le diamètre au-dessus duquel on trouve $10 \%$ des micelles (D10) et le diamètre au-dessus duquel on trouve $90 \%$ des micelles (D90). Pour chaque paramètre, les données analysées résultent de la moyenne de 8 mesures.

\section{Aptitude des laits à coaguler par la présure}

Les tests rhéologiques sont réalisés la veille des fabrications fromagères à l'aide du Formagraph (société Foss Electric, Danemark) sur les laits individuels écrémés. Les mesures sont faites en double au pH initial $\left(\mathrm{pH}_{0}\right)$ et au $\mathrm{pH}$ standardisé à $6,60\left(\mathrm{pH}_{\mathrm{s}}\right)$ par ajout d'acide lactique dilué au 1/10 . 
L'emprésurage est réalisé à $32^{\circ} \mathrm{C}$, avec une dose d'extrait de présure liquide à $520 \mathrm{mg}$ de chymosine active/ (Granday, Beaune) diluée dans un tampon pipérazine hexahydrate $(0,025 \mathrm{~mol} / \mathrm{h})$ de $\mathrm{pH} 5,3$. À partir du tracé graphique obtenu, on mesure le temps de gélification ( $R$, en min), le temps nécessaire pour que le caillé possède, après gélification, une certaine consistance matérialisée par un écartement de $20 \mathrm{~mm}$ entre les 2 branches du graphe (K20, en min) et la consistance du caillé 30 min après emprésurage ( $A 30$, en $\mathrm{mm}$ ).

Chaque jour où étaient réalisées des mesures rhéologiques au Formagraph, un lait témoin reconstitué à $12 \%$ dans du $\mathrm{CaCl}_{2} 0,01 \mathrm{~mol} / /$, à partir d'une poudre de lait écrémé low heat (INRA, Poligny) était ajouté aux laits expérimentaux analysés pour tester la dérive éventuelle de l'appareil.

\section{Analyses chimiques}

Toutes les analyses chimiques sont réalisées en double sur chaque échantillon.

- Extrait sec (ES) : détermination par dessication à l'étuve à $101^{\circ} \mathrm{C}$ jusqu'à poids constant des échantillons selon la norme FIL 4A (1982):

- Matière grasse (MG) : méthode acido-butyrométrique de Gerber selon la nome AFNOR V04210 (1971) pour les laits (à la réception et en cuve après addition des levains) et le lactosérum exsudé lors du découpage du caillé en cuve et méthode butyrométrique de Heiss (1961) modifiée par Pien (1976) pour les fromages âgés de $24 \mathrm{~h}$ et 8 semaines ;

- Calcium et phosphore: dosage fluorimétrique du calcium (Ca) à l'aide du calcimètre Corning 940 (Corning France, Le Vésinet) et dosage colorimétrique du phosphore $(\mathrm{P})$ selon la norme FIL 42 (1967) effectués sur la fraction totale (CaT et PT) du lait écrèmé et sur la fraction soluble (CaS et PS) obtenue par ultrafiltration de lait écrémé à l'aide de cônes Centriflo CF 25 (Amicon, Lexiton, États-Unis) constitués d'une membrane avec un seuil de coupure de $10000 \mathrm{Da}$, centrifugés à $1000 \mathrm{~g}, 20 \mathrm{~min}$.

- Chlorures : dosage selon la norme FIL 17A (1972) modifiée par ajout de nitrobenzène comme dans la méthode de Silverman et al (1959) pour les fromages âgés de 8 semaines.

\section{Azote total et fractions azotées}

Dosage par la méthode Kjeldahl automatisée (Vapodest 6, société Gerhardt, OSI, Paris) de l'azote total (NT) du lait, du lactosérum et du fromage âgé de 24 h, 2 et 8 semaines, de l'azote des fractions non protéique (NPN) et non caséique (NCN) du lait écrémé, préparées selon la méthode de Rowland (1938).

A partir des dosages des fractions azotées et minérales des laits (NT, NPN, NCN, CaT, CaS, PT et PS), on a calculé les teneurs (en $\mathrm{g} / \mathrm{kg}$ ) en matière azotée totale (MAT $=N T \times 6,38$ ), en caséine $(\mathrm{CNE}=(\mathrm{NT}-\mathrm{NCN}) \times 6,38)$, en protéines totales (prot $=(N T-N P N) \times 6,38)$, en calcium colloïdal $(\mathrm{CaC}=\mathrm{CaT}-\mathrm{CaS})$ et en phosphore colloïdal (PC = PT - PS) des laits ainsi que le degré de minéralisation calcique des micelles de caséines (MIC $=\mathrm{CaC} / \mathrm{CNE} \times 100)$.

\section{Caséines}

Analyse quantitative des caséines des laits $\left(\alpha_{s}, \beta\right.$ et $\kappa$ ) après séparation électrophorétique et lecture densitométrique (lecteur Vernon) de plaques d'électrophorèse selon la technique d'Uriel (1966) modifiée par Gripon et al (1975). La caséine entière est préparée par dissolution dans $5 \mathrm{ml}$ d'urée $9 \mathrm{~mol} / \mathrm{l}$ contenant $1 \%$ de $\beta$-mercaptoéthanol, de $0,6 \mathrm{~g}$ du précipité à $\mathrm{pH} 4,6$, récupéré lors de la préparation du NCN du lait. Les différentes caséines sont ensuite séparées sur gel de polyacrylamide-agarose (PAGE) à $\mathrm{pH} 8,6$, précipitées au TCA $12 \%$ et colorées au Bleu de Coomassie R250. Leurs pourcentages dans la caséine totale sont déterminés après lecture en transparence de l'intensité de coloration des bandes selon la technique décrite par Collin et al (1987) en considérant que la fixation du colorant a lieu dans les mẽmes proportions pour toutes les bandes (Ribadeau-Dumas et Grappin, 1989). Les caséines sont exprimées en proportion de la surface totale intégrée.

\section{Calcul des rendements fromagers}

- Rendement brut (RB) : poids $(\mathrm{kg})$ de fromage frais $(24 \mathrm{~h})$ obtenu à partir de $100 \mathrm{~kg}$ de lait.

- Rendement corrigé (RC) : pour tenir compte des variations de teneur en substances sèches totales des fromages, les rendements bruts peuvent être corrigés en utilisant la formule proposée par Maubois et Mocquot (1967) soit : RC = $R B \times\left(E S_{1}-E S_{s}\right) /\left(E S_{n}-E S_{s}\right)$ dans laquelle $E S_{s}$, $E S_{\text {, et }} E S_{\text {" }}$ représentent respectivement les extraits secs du lactosérum de fin d'égouttage, du fromage âgés de $24 \mathrm{~h}$, et la moyenne des extraits secs des fromages âgés de $24 \mathrm{~h}$. 
- Coefficients de récupération : ils expriment la part d'un composant du lait (ES, MAT, MG) retrouvé dans le fromage. Les calculs sont effectués à partir des analyses des laits et des lactosérums d'après Mietton (1986).

Pertes en fines de fromagerie : elles sont calculées par la différence entre l'extrait sec du sérum entier $\left(E S_{s}\right)$ et l'extrait sec du sérum centrifugé $\left(E S_{S c}\right)$ rapporté à l'extrait sec du sérum entier $\left(\mathrm{ES}_{\mathrm{S}}\right)$.

\section{Analyses statistiques}

Les principaux paramètres statistiques (moyenne, écart type) ont été déterminés pour chaque variable dans chacune des 2 populations. $\mathrm{La}$ matrice des corrélations simples entre variables a été calculée pour l'ensemble des données analytiques.

L'incidence du facteur "variant génétique" a été testée par une analyse de variance. Deux modèles linéaires différents ont été utilisés selon le type de variables à analyser. L'effet du génotype de la caséine $\beta$ sur les variables de «composition du lait" a été analysé à l'aide d'un modèle à 2 facteurs: le "génotypen en effet fixe et la "vache" en effet aléatoire, puisque certains animaux étaient prélevés plusieurs fois. Pour les variables liées à la fabrication fromagère, le modèle linéaire utilisé prend en compte aussi le "jour de fabrication" en effet fixé, car il a été démontré, dans l'atelier expérimental de l'INRA de Jouy-en-Josas, qu'il existe, dans les conditions de minifabrications de fromages à pâte pressée, un effet du "jour de fabrication" sur les caractéristiques des fabrications fromagères (rendements, composition) (Nuyts-Petit, 1991).

Le traitement statistique des résultats a été effectué à l'aide du logiciel "MICROSTAT" élaboré par l'ITCF (Boigneville) (1984) à l'exception des analyses de variance à deux ou trois facteurs réalisées avec le logiciel SAS (SAS Institute, États-Unis) selon la procédure GLM.

\section{RÉSULTATS}

\section{Composition physico-chimique des laits}

Les résultats sont rassemblés dans le tableau II.
Les 2 familles de laits $\beta-C n C$ et $\beta-C n A$ se différencient par leur $\mathrm{pH}$ initial. Les laits de type $\beta$-Cn $C$ sont significativement $(P<$ $0,01)$ plus acides que les laits $\beta-C n A(6,64$ contre 6,72).

La proportion d'azote non protéique dans la matière azotée totale est plus faible dans les laits $\beta-C n A$ que dans les laits $\beta-C n C$ $(5,4$ contre $6,1 \% ; P<0,05)$. En ce qui concerne les autres fractions azotées, seule une tendance est à noter : les laits $\beta-C n A$ semblent plus riches en matières azotées totales, plus précisément en caséines $(22,8$ contre $24,1 \mathrm{~g} / \mathrm{kg}$ ). La matière azotée totale des laits et le taux de caséines sont fortement corrélés $(r=0,953 ; P<0,001)$.

La teneur en calcium total des laits varie de 0,97 à $1,28 \mathrm{~g} / \mathrm{kg}$. Les laits $\beta-C$ n A sont significativement plus riches en calcium total que les laits $\beta$-Cn C $(1,20$ contre $1,08 \mathrm{~g} / \mathrm{kg}$; $P<0,01)$ et en calcium colloïdal $(0,86$ contre $0,70 \mathrm{~g} / \mathrm{kg} ; P<0,01)$ et significativement plus pauvres en calcium soluble $(0,34$ contre $0,38 \mathrm{~g} / \mathrm{kg} ; P<0,01)$. II en résulte que l'indice de minéralisation calcique des caséines est plus élevé pour les laits de type $\beta-\mathrm{Cn} A$ (36 contre $31 ; P<0,01$ ). La proportion de calcium soluble est corrélativement plus faible pour les laits $\beta-\mathrm{Cn}$ A (28 contre $35 \%$ du calcium total ; $P<0,01$ ).

La détermination des proportions des principales caséines à partir des électrophorèses montre que les laits $\beta-C n C$ se distinguent des laits $\beta-C n$ A par un pourcentage plus élevé de $\beta-C n$ ( 40,8 contre $32,5 \% ; P<0,01)$. L'incertitude de mesure élevée sur la lecture des faibles pourcentages de caséines n'a pas permis de discriminer les laits des 2 génotypes à l'aide du pourcentage de $\kappa-\mathrm{Cn}$. Cependant, les laits $\beta$-Cn A sont plus riches en caséines avec un pourcentage cumulé de $\alpha_{\mathrm{s}}$-Cn et $\beta$-Cn plus faible $(76,3$ contre $85,4 \%)$ : ils sont donc vraisemblablement plus riches en $\kappa-\mathrm{Cn}$.

Le diamètre moyen des micelles de caséines et la répartition des diamètres 
Tableau II. Composition des laits (effets des variants de la caséine $\beta$ ). Milk composition (effect of $\beta$-casein variants).

\begin{tabular}{|c|c|c|c|}
\hline Variables & $\begin{array}{c}\text { Moye } \\
\beta C C \\
(\mathrm{n}=9)\end{array}$ & $\begin{array}{c}\beta A A \\
(n=6)\end{array}$ & $\mathrm{Pa}$ \\
\hline $\mathrm{pH}$ lait entier & $\begin{array}{l}6,64 \\
(0,04)\end{array}$ & $\begin{array}{c}6,72 \\
(0,07)\end{array}$ & ** \\
\hline Matière grasse $(\mathrm{g} / \mathrm{kg})$ & $\begin{array}{l}36,2 \\
(3,5)\end{array}$ & $\begin{array}{l}34,5 \\
(5,5)\end{array}$ & NS \\
\hline Matières azotées totales $(\mathrm{g} / \mathrm{kg})$ & $\begin{array}{l}29,51 \\
(1,87)\end{array}$ & $\begin{array}{l}30,88 \\
(0,81)\end{array}$ & NS \\
\hline Protéines totales $(\mathrm{g} / \mathrm{kg})$ & $\begin{array}{c}27,72 \\
(1,77)\end{array}$ & $\begin{array}{l}29,19 \\
(0,71)\end{array}$ & 0,09 \\
\hline Caséines totales $(\mathrm{g} / \mathrm{kg})$ & $\begin{array}{l}22,76 \\
(1,52)\end{array}$ & $\begin{array}{l}24,07 \\
(0,59)\end{array}$ & NS \\
\hline Caséines/Protéines (\%) & $\begin{array}{l}82,1 \\
(1,0)\end{array}$ & $\begin{array}{l}82,4 \\
(1,6)\end{array}$ & NS \\
\hline Azote non protéique/MAT (\%) & $\begin{array}{l}6,06 \\
(0,50)\end{array}$ & $\begin{array}{l}5,43 \\
(0,85)\end{array}$ & * \\
\hline Matière grasse/caséines & $\begin{array}{c}1,60 \\
(0,23)\end{array}$ & $\begin{array}{c}1,43 \\
(0,21)\end{array}$ & NS \\
\hline Phosphore total $(\mathrm{g} / \mathrm{kg})$ & $\begin{array}{c}0,94 \\
(0,31)\end{array}$ & $\begin{array}{l}0,90 \\
(0,05)\end{array}$ & NS \\
\hline Ca total $(\mathrm{g} / \mathrm{kg})$ & $\begin{array}{l}1,08 \\
(0,08)\end{array}$ & $\begin{array}{l}1,20 \\
(0,08)\end{array}$ & \#\# \\
\hline Ca colloïdal (g/kg) & $\begin{array}{l}0,70 \\
(0,06)\end{array}$ & $\begin{array}{c}0,86 \\
(0,05)\end{array}$ & ** \\
\hline Ca soluble $(\mathrm{g} / \mathrm{kg})$ & $\begin{array}{l}0,38 \\
(0,05)\end{array}$ & $\begin{array}{l}0,34 \\
(0,07)\end{array}$ & ** \\
\hline Ca soluble/Ca total (\%) & $\begin{array}{l}35,1 \\
(3.7)\end{array}$ & $\begin{array}{l}28,0 \\
(4,5)\end{array}$ & ** \\
\hline $\begin{array}{l}\text { Minéralisation calcique } \\
\text { des micelles }(\%)\end{array}$ & $\begin{array}{l}30,9 \\
(3,2)\end{array}$ & $\begin{array}{r}35,8 \\
(1,7)\end{array}$ & ** \\
\hline$\beta-C n$ ( $\%$ caséine totale) & $\begin{array}{l}40,8 \\
(4,7)\end{array}$ & $\begin{array}{l}32,5 \\
(6,0)\end{array}$ & ** \\
\hline$\alpha_{s}-C n$ (\% caséine totale) & $\begin{array}{l}44,6 \\
(6,8)\end{array}$ & $\begin{array}{l}43,8 \\
(8,7)\end{array}$ & NS \\
\hline$\kappa-C n$ (\% caséine totale) & $\begin{array}{c}4,1 \\
(2,0)\end{array}$ & $\begin{array}{l}3,5 \\
(1,0)\end{array}$ & NS \\
\hline $\mathrm{DMO}(\mathrm{nm})$ & (33) & $\begin{array}{l}187 \\
(6)\end{array}$ & $\star \star * \star$ \\
\hline $\mathrm{D} 10(\mathrm{~nm})$ & $\begin{array}{l}124 \\
(17)\end{array}$ & $\begin{array}{l}78 \\
(5)\end{array}$ & 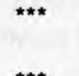 \\
\hline $\mathrm{D} 90(\mathrm{~nm})$ & $\begin{array}{l}87 \\
(13)\end{array}$ & $\begin{array}{l}54 \\
(4)\end{array}$ & *** \\
\hline
\end{tabular}

a $P$. seuil de probabilité suivant le modèle à 2 facteurs (effet "génotype" et effet "vache" en aléatoire); NS : $P>0,10 ; *^{*}: P<0,05 ;^{* *}: P<0,01 ;^{* * *}: P<0,001$. 
micellaires autour de cette moyenne sont les paramètres les plus significatifs pour discriminer les 2 génotypes. En effet, les laits $\beta-C n C$ se différencient des laits $\beta-C n A$ par des diamètres micellaires beaucoup plus élevés (293 contre $187 \mathrm{~nm} ; P<0,001$ ) mais aussi par une courbe de répartition gaussienne autour de cette moyenne beaucoup plus aplatie. On note des liens étroits entre la dimension moyenne des micelles et les paramètres de dispersion D10 et D90 (respectivement $r=0,961$ et $r=0,977 ; P<$ $0,001)$. Enfin, le diamètre moyen des micelles présente une corrélation négative avec la teneur en calcium colloïdal ( $r=$ $-0,773 ; P<0,001)$ et avec l'indice de minéralisation calcique $(r=-0,719 ; P<0,001)$.

\section{Aptitude des laits à la coagulation par la présure}

Les résultats sont rassemblés dans le tableau III.

Les analyses ont d'abord été effectuées au $\mathrm{pH}$ initial $\left(\mathrm{pH}_{0}\right)$ des laits. Dans ce cas, seul le temps de gélification permet de discriminer les laits des 2 génotypes; les laits $\beta-C n C$ coagulent 2 fois plus vite que les laits $\beta-C n A$ (respectivement 7,6 contre 16,6 $\min ; P<0,001)$. Les temps de gélification (R) sont très corrélés au $\mathrm{pH}_{0}$ des laits ( $r=$ $0,844 ; P<0,001)$.

Une seconde mesure des paramètres de coagulation a été réalisée après standardisation des $\mathrm{pH}$ des laits à $6,60\left(\mathrm{pH}_{\mathrm{s}}\right)$. Bien que l'écart entre les valeurs de $R$ des laits des 2 génotypes diminue de $50 \%$, on obtient toujours une valeur significativement $(P<0,001)$ plus faible pour les laits $\beta$-Cn $C$ ( 7,6 contre $10,9 \mathrm{~min}$ ).

Les temps de raffermissement (K20) à $\mathrm{pH}_{\mathrm{s}}$ sont 2 fois plus courts pour les laits $\beta-\mathrm{Cn}$ $A$ que pour les laits $\beta-C n C$ (respectivement, $6,9$ contre $13,6 \mathrm{~min} ; P=0,05)$. Le K20 et la fermeté du gel 30 min après l'emprésurage
Tableau III. Coagulation des laits à la présure (effet des variants de la caséine $\beta$ ).

Milk rennet coagulation (effect of $\beta$-casein variants).

\begin{tabular}{|c|c|c|c|}
\hline Variables & $\begin{array}{c}\text { Moyennes } \\
\text { B CC } \\
(\mathrm{n}=9)\end{array}$ & $\begin{array}{c}\text { écart type) } \\
\beta A A \\
(n=6)\end{array}$ & $\mathrm{Pa}$ \\
\hline \multicolumn{4}{|l|}{ pH initial } \\
\hline$R(\min )$ & $\begin{array}{c}7,6 \\
(1,1)\end{array}$ & $\begin{array}{c}16,6 \\
(5,4)\end{array}$ & $* * *$ \\
\hline $\mathrm{K} 20$ (min) & $\begin{array}{c}13,6 \\
(5,4)\end{array}$ & $\begin{array}{c}12,6 \\
(8,8)\end{array}$ & NS \\
\hline A30 $(\mathrm{mm})$ & $\begin{array}{c}24,5 \\
(4,4)\end{array}$ & $\begin{array}{c}24,2 \\
(11,2)\end{array}$ & NS \\
\hline \multicolumn{4}{|c|}{ pH standardisé } \\
\hline$R(\min )$ & $\begin{array}{c}7,6 \\
(1,1)\end{array}$ & $\begin{array}{c}10,9 \\
(1,4)\end{array}$ & $* * *$ \\
\hline $\mathrm{K} 20$ (min) & $\begin{array}{c}13,6 \\
(5,4)\end{array}$ & $\begin{array}{c}6,9 \\
(2,1)\end{array}$ & * \\
\hline $\mathrm{A} 30(\mathrm{~mm})$ & $\begin{array}{c}24,5 \\
(4,4)\end{array}$ & $\begin{array}{c}36,7 \\
(6,5)\end{array}$ & ** \\
\hline
\end{tabular}

a $P$ : seuil de probabilité suivant le modèle à 2 facteurs (effet "génotype» et effet "vache" en aléatoire) ; NS : $P>0,10 ; * P<0,05 ; \cdots: P<0,01$; $\cdots: P=0,001$.

du lait (A30) sont corrélés négativement ( $r=$ $-0,837 ; P<0,001)$ de sorte que, quel que soit le $\mathrm{pH}$ et donc $\mathrm{R}$, le rapport K20/R reste assez constant pour chaque lait et environ 2 fois plus petit pour les laits $\beta-C n$ A que pour les laits $\beta$-Cn $\mathrm{C}$ (respectivement à $\mathrm{pH}_{0}$ : 0,76 contre 1,8 et à $\mathrm{pH}_{\mathrm{s}}: 0,63$ contre 1,8 ). Le coagulum $\beta$-Cn A possède une valeur A30 moyenne bien supérieure ( 1,5 fois) à celle du coagulum $\beta-C n C$ (respectivement, 36,7 contre $24,5 \mathrm{~mm} ; P<0,01$ ).

Le K20 est corrélé négativement, de façon très hautement significative, aux teneurs en protéines $(r=-0,807 ; P<$ $0,001)$ et en caséine $(r=-0,791 ; P<$ $0,001)$. La fermeté maximale $\mathrm{A} 30 \mathrm{à}_{\mathrm{s}}$ et la teneur en protéines des laits sont également bien corrélées $(r=0,649 ; P<0,01)$. 
La fermeté maximale est aussi fortement liée à la concentration en calcium colloïdal des laits $(r=0,832 ; P<0,001)$. Enfin on peut noter une corrélation négative entre la dimension moyenne des micelles, la répartition des micelles autour de cette moyenne (D10 et D90) d'une part, et la fermeté maximale du coagulum d'autre part (respectivement $r=-0,756 ; r=-0,694 ; r=-0,729$; $P<0,01)$.

\section{Déroulement des fabrications}

\section{Rendements et composition des fromages frais}

Les résultats sont rassemblés dans le tableau IV.

Les cinétiques d'acidification au cours du pressage des fromages sont en moyenne très semblables pour les 2 types de lait mis en fabrication. Le $\mathrm{pH}$ des fromages âgés de $24 \mathrm{~h}$ n'est pas significativement différent entre les fromages fabriqués avec le lait de génotype $\mathrm{C}$ ou $\mathrm{A}$ (respectivement 5,17 et 5,21).

L'extrait sec (ES) du sérum est significativement plus important pour le lactosérum $\beta-C n C$ que pour le lactosérum $\beta-C n A$ (respectivement 7,8 contre $7,2 \mathrm{~g} / 100 \mathrm{~g} ; P<$ $0,05)$. Les pertes en fines, plus importantes dans le lactosérum $\beta-C n C(11,1$ contre 5,8 ; $P<0,01)$ correspondent à de la matière grasse (MG) mal retenue comme le prouve la teneur en MG des sérums (respectivement 5,0 contre $10,4 \mathrm{~g} / \mathrm{l}$ en moyenne, pour les fabrications $\beta-C n$ A et $\beta-C n C ; P<$ $0,01)$. Ce résultat est illustré par les photos des caillés en cuve de fabrication (fig 2). Les pourcentages de récupération, dans le caillé, de la MG, et de l'ES sont très significativement plus faibles en présence du variant $C$, ce qui confirme les résultats précédents.
Les rendements dépendent, outre la richesse du lait, des pertes dans le sérum et les laits $\beta-C n C$ se caractérisent par des rendements médiocres. Les rendements bruts et corrigés de l'ES des fromages frais

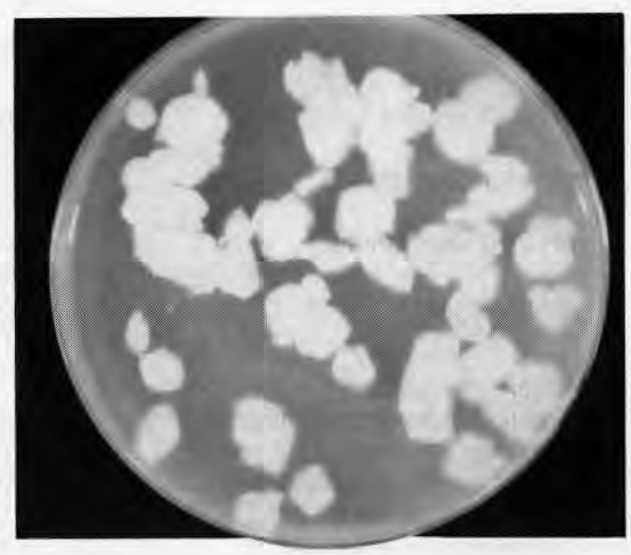

CAILLE B AA

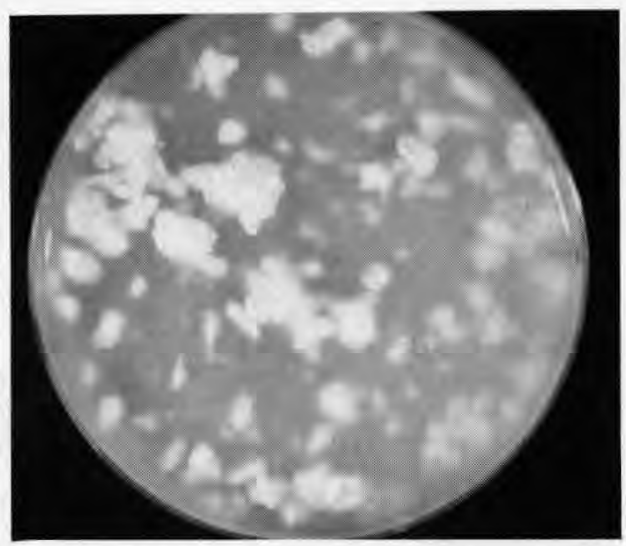

CAILLE B CC

Fig 2. Aspect des 2 types de caillé après découpage et chauffage (effet des variants de la caséine $\beta$ ). Aspect of the 2 types of curd after cutting and cooking (effect of $\beta$-casein variants). 
Tableau IV. Acidification au cours de la fabrication, rendements fromagers et composition des fromages frais à $24 \mathrm{~h}$ (effet des variants de la caséine $\beta$ ).

Acidification during cheese making, cheese yields and fresh cheese composition at $24 \mathrm{~h}$ (effect of $\beta$-casein variants).

\begin{tabular}{|c|c|c|c|}
\hline Variables & $\begin{array}{c}\text { Moyenne } \\
\beta C C \\
(\mathrm{n}=9)\end{array}$ & $\begin{array}{c}\text { cart type) } \\
\beta A A \\
(\mathrm{n}=6)\end{array}$ & $\mathrm{Pa}$ \\
\hline \multicolumn{4}{|l|}{ Acidification } \\
\hline $\mathrm{pH}$ lait + levains & $\begin{array}{l}6,57 \\
(0,09)\end{array}$ & $\begin{array}{c}6,64 \\
(0,10)\end{array}$ & NS \\
\hline $\mathrm{pH} 1 \mathrm{er}$ retournement & $\begin{array}{l}6,45 \\
(0,07)\end{array}$ & $\begin{array}{c}6,53 \\
(0,08)\end{array}$ & NS \\
\hline $\mathrm{pH} 2^{\circ}$ retournement & $\begin{array}{l}6,39 \\
(0,08)\end{array}$ & $\begin{array}{l}6,47 \\
(0,11)\end{array}$ & NS \\
\hline $\mathrm{pH}$ démoulage & $\begin{array}{l}5,16 \\
(0,16)\end{array}$ & $\begin{array}{l}5,26 \\
(0,26)\end{array}$ & NS \\
\hline \multicolumn{4}{|l|}{ Rendements en frais } \\
\hline $\begin{array}{l}\text { Coefficient de récupération } \\
\text { en matière sèche }(\%)\end{array}$ & $\begin{array}{c}38,4 \\
(2,8)\end{array}$ & $\begin{array}{c}44,9 \\
(2,5)\end{array}$ & $* *$ \\
\hline $\begin{array}{l}\text { Coefficient de récupération } \\
\text { en matière azotée }(\%)\end{array}$ & $\begin{array}{l}73,2 \\
(5,2)\end{array}$ & $\begin{array}{l}77,9 \\
(3,0)\end{array}$ & 0,07 \\
\hline $\begin{array}{l}\text { Coefficient de récupération } \\
\text { en matière grasse }(\%)\end{array}$ & $\begin{array}{c}63,5 \\
(10,9)\end{array}$ & $\begin{array}{l}82,6 \\
(10,0)\end{array}$ & ** \\
\hline Rendement brut (\%) & $\begin{array}{l}7,94 \\
(0,68)\end{array}$ & $\begin{array}{c}8,99 \\
(0,49)\end{array}$ & $* \star \star \star$ \\
\hline Rendement corrigé (\%) & $\begin{array}{c}7,83 \\
(0,72)\end{array}$ & $\begin{array}{l}9,21 \\
(0,58)\end{array}$ & $\star \star \star \star ~$ \\
\hline \multicolumn{4}{|l|}{ Composition du lactosérum } \\
\hline Extrait sec (\%) & $\begin{array}{l}7,8 \\
(0,2)\end{array}$ & $\begin{array}{l}7,2 \\
(0,3)\end{array}$ & * \\
\hline Azote total ( $\mathrm{g} \mathrm{d} \mathrm{N} / \mathrm{kg})$ & $\begin{array}{l}7,92 \\
(0,66)\end{array}$ & $\begin{array}{l}8,28 \\
(0,67)\end{array}$ & NS \\
\hline Matière grasse (\%) & $\begin{array}{l}10,4 \\
(3,1)\end{array}$ & $\begin{array}{l}5,0 \\
(2,4)\end{array}$ & ** \\
\hline Fines de fromagerie & $\begin{array}{l}11,1 \\
(4,1)\end{array}$ & $\begin{array}{l}5,8 \\
(3,0)\end{array}$ & ** \\
\hline \multicolumn{4}{|c|}{ Composition des fromages à $24 h$} \\
\hline $\mathrm{pH}$ & $\begin{array}{l}5,17 \\
(0,20)\end{array}$ & $\begin{array}{c}5,21 \\
(0,19)\end{array}$ & NS \\
\hline Extrait sec $(\mathrm{g} / 100 \mathrm{~g})$ & $\begin{array}{l}55,32 \\
(1,80)\end{array}$ & $\begin{array}{l}57,21 \\
(1,30)\end{array}$ & 0,09 \\
\hline Azote total ( $\mathrm{g} \mathrm{d}$ 'N/kg) & $\begin{array}{c}4,32 \\
(0,30)\end{array}$ & $\begin{array}{c}4,23 \\
(0,31)\end{array}$ & NS \\
\hline Matière grasse $(\mathrm{g} / 100 \mathrm{~g})$ & $(2,3)$ & $\begin{array}{l}24,5 \\
(2,1)\end{array}$ & * \\
\hline Gras/Sec (\%) & $\begin{array}{l}38,1 \\
(4,0)\end{array}$ & $\begin{array}{l}42,9 \\
(2,8)\end{array}$ & * \\
\hline $\begin{array}{l}\text { Extrait sec du fromage } \\
\text { dégraissé }(\mathrm{g} / 100 \mathrm{~g})\end{array}$ & $\begin{array}{l}43,4 \\
(2,4)\end{array}$ & $\begin{array}{l}43,3 \\
(1,9)\end{array}$ & NS \\
\hline
\end{tabular}

a $P$ : seuil de probabilité suivant le modèle à 3 facteurs (effets "génotypen et "jour de fabrication", effet "vache" en aléatoire). NS : $P>0,10 ;{ }^{*}: P<0,05 ;{ }^{* *}: P<0,01 ; \cdots * P<0,001$. 
sont beaucoup plus faibles pour les fabrications de type $\beta$-Cn $C$ (rendement corrigé $7,8 \%$ pour $\beta$-Cn $\mathrm{C}$ contre $9,2 \%$ pour $\beta-\mathrm{Cn} \mathrm{A}$; $P<0,001)$.

Les fromages $\beta-C n A$ étant plus riches en $M G$ que les fromages $\beta$-Cn $C(24,5$ contre $21,1 \mathrm{~g} / 100 \mathrm{~g}$ de fromage ; $P<0,05$ ), ils tendent à être plus secs $(57,2$ contre $55,3 \%$ ), ce que traduit la corrélation entre la MG des fromages et leur ES ( $r=0,625$; $P<0,05)$. Afin d'occulter les différences de teneurs en MG liées au génotype, on peut analyser l'extrait sec des fromages dégraissés (ESFD). On constate que l'ESFD des fromages $\beta$-Cn $C(43,4 \%)$ est peu différent de celui des fromages $\beta-C n A$ $(43,3 \%)$. Il en résulte que le gras/sec (G/S) des fromages $\beta-C n C$ est significativement plus faible que celui des fromages $\beta-C n A$ (respectivement, en moyenne, 38,1 et 42,9\%; $P<0,05)$.

\section{Caractéristiques des fromages en cours d'affinage}

Les résultats sont présentés dans le tableau V.

Tableau V. Composition des fromages après 2 et 8 semaines d'affinage (effet des variants de la caséine $\beta$ ).

Cheese composition after 2 and 8 weeks of ripening (effect of $\beta$-casein variants).

\begin{tabular}{|c|c|c|c|}
\hline \multirow[t]{2}{*}{ Variables } & \multicolumn{2}{|c|}{ Moyennes ( \pm écart type) } & \multirow[t]{2}{*}{$P$ a } \\
\hline & $\begin{array}{l}\beta C C \\
(n=9)\end{array}$ & $\begin{array}{c}\beta A A \\
(\mathrm{n}=6)\end{array}$ & \\
\hline \multicolumn{4}{|l|}{ Fromages à 2 semaines } \\
\hline $\mathrm{pH}$ & $\begin{array}{c}5,15 \\
(0,05)\end{array}$ & $\begin{array}{c}5,23 \\
(0,07)\end{array}$ & NS \\
\hline Extrait sec $(\mathrm{g} / 100 \mathrm{~g})$ & $\begin{array}{c}58,19 \\
(1,36)\end{array}$ & $\begin{array}{c}59,68 \\
(0,96)\end{array}$ & NS \\
\hline Azote total ( $\mathrm{g}$ d'N/kg) & $\begin{array}{c}4,73 \\
(0,43)\end{array}$ & $\begin{array}{c}4,74 \\
(0,78)\end{array}$ & NS \\
\hline \multicolumn{4}{|l|}{ Fromages à 8 semaines } \\
\hline $\mathrm{pH}$ & $\begin{array}{c}5,39 \\
(0,17)\end{array}$ & $\begin{array}{c}5,39 \\
(0,11)\end{array}$ & NS \\
\hline Extrait sec $(\mathrm{g} / 100 \mathrm{~g})$ & $\begin{array}{c}58,27 \\
(1,69)\end{array}$ & $\begin{array}{l}60,07 \\
(1,05)\end{array}$ & NS \\
\hline Azote total ( $\mathrm{g}$ d'N/kg) & $\begin{array}{c}4,73 \\
(0,31)\end{array}$ & $\begin{array}{c}4,47 \\
(0,26)\end{array}$ & NS \\
\hline Matière grasse $(\mathrm{g} / 100 \mathrm{~g})$ & $\begin{array}{c}21,4 \\
(3,0)\end{array}$ & $\begin{array}{l}25,8 \\
(1,8)\end{array}$ & $\star \star *$ \\
\hline Gras/Sec (\%) & $\begin{array}{c}36,7 \\
(4,9)\end{array}$ & $\begin{array}{c}42,9 \\
(2,5)\end{array}$ & $* *$ \\
\hline $\begin{array}{l}\text { Extrait sec du fromage } \\
\text { dégraissé }(\mathrm{g} / 100 \mathrm{~g})\end{array}$ & $\begin{array}{c}46,9 \\
(2,3)\end{array}$ & $\begin{array}{c}46,2 \\
(1,0)\end{array}$ & NS \\
\hline $\mathrm{NaCl}(\mathrm{g} / 100 \mathrm{~g})$ & $\begin{array}{c}1,52 \\
(0,35)\end{array}$ & $\begin{array}{c}1,32 \\
(0,19)\end{array}$ & NS \\
\hline
\end{tabular}

a $P$ : seuil de probabilité suivant le modèle à 3 facteurs (effets "génotypen et ujour de fabrication", effet "vache" en aléatoire). NS : $P>0,10 ;{ }^{*}: P<0,05 ;{ }^{* *}: P<0,01 ;{ }^{* * *}: P<0,001$. 
Au cours de l'affinage, le $\mathrm{pH}$ augmente de 0,2 unité. À 8 semaines, il se situe autour de 5,4 .

Sur les fromages âgés de $24 \mathrm{~h}, 2$ et 8 semaines, 2 paramètres discriminent les fromages fabriqués avec les laits des 2 génotypes : la MG du fromage $(P<0,01)$ et le rapport $\mathrm{G} / \mathrm{S}(P<0,01)$. L'ES des minifromages, qui augmente entre $24 \mathrm{~h}$ et 2 semaines, avec le saumurage des fromages, a tendance à se stabiliser au cours de l'affinage. Le paraffinage des minifromages a donc fortement limité les pertes d'eau par évaporation, objectif qui était recherché.

Enfin, le saumurage n'a pas été significativement différent pour les fromages fabriqués avec les laits des 2 types génétiques: il n'y a pas de corrélation entre les taux de $\mathrm{NaCl}$ et les ES des fromages. Les teneurs en $\mathrm{NaCl}$ se situent entre 1,3 et $1,5 \mathrm{~g} / 100 \mathrm{~g}$ de fromage.

\section{DISCUSSION}

D'une manière générale, les résultats de composition des laits concordent avec ce que l'on sait de la structure des micelles de caséines et des équilibres minéraux du lait. La $\kappa-C n$ étant localisée à la surface de la micelle, plus celle-ci est de taille élevée, plus en proportion, elle est riche en $\alpha_{\mathrm{s}}$-Cn et $\beta-C n$ et pauvre en $\kappa-C n$ (Davies et Law, 1983 ; Donnelly et al, 1984 ; Lenoir, 1985 ; Delacroix-Buchet et al, 1993). Le fort diamètre des micelles des laits $\beta-C n C$ a déjà été montré par Nuyts-Petit (1991), dans une étude précédente des laits de vaches tarentaises. Dans cette même étude, Nuyts-Petit a démontré la plus grande richesse en $\mathrm{k}-\mathrm{Cn}$ des micelles $\beta-C n$ en séparant les caséines par chromatographie FPLC d'échange d'ions. L'auteur a aussi trouvé une bonne corrélation entre le diamètre moyen des micelles et les paramètres de dispersion autour de la moyenne (D10 et
D90). Ce dernier résultat est en revanche moins conforme à la bibliographie puisque de nombreux auteurs ont travaillé sur des micelles de caséines artificielles. Cependant, Morini et al (1975) ont montré que les laits possédant des micelles de grand diamètre avaient une répartition des tailles de micelles autour de cette moyenne plus hétérogène. La plage de variation de la teneur en calcium total est conforme aux données de Alais (1984). La plus forte teneur en calcium soluble des laits $\beta-\mathrm{Cn} C$ pourrait être reliée à leur $\mathrm{pH}$ plus acide qui entraîne une solubilisation des sels minéraux micellaires (Brulé et al, 1974). La corrélation négative observée entre le diamètre moyen des micelles de caséine et la teneur en calcium colloïdal ou l'indice de minéralisation calcique a aussi été mentionnée dans les laits de chèvre par Remeuf et al (1989) et le coefficient de corrélation est du même ordre que celui annoncé par Holt et Muir (1978) pour des laits de mélange. Ce fait semble être en contradiction avec la composition des micelles de caséine de grand diamètre. Comme l'ont montré Dickson et Perkins (1971), et Brulé et Lenoir (1987) chaque phosphosérine a la possibilité de fixer un atome de $\mathrm{Ca}^{2+}$. Le pouvoir chélatant des caséines est d'autant plus important que le taux de phosphosérine est élevé. Les $\alpha_{s}-C n$ possèdent plus de sites phosphorylés (10 à 13 sites pour $\alpha_{\mathrm{s} 2}-\mathrm{Cn} ; 8$ à 9 sites pour $\alpha_{s 1}-\mathrm{Cn}$ ) que la $\beta$-Cn ( 4 à 5 sites). En fait, ainsi que lont déjà observé Remeuf et al (1989), l'augmentation de taille des micelles s'accompagne d'une substitution de l' $\alpha_{s}-C n$ (la plus chélatante pour le calcium) par la $\beta-C n$. De plus, le variant $C$ de la $\beta-C n$ se caractérise par la non-phosphorylation du résidu Ser 35 . Au total, il s'avère que les laits $\beta-C n C$ présentent une quantité moindre de phosphosérines, donc fixent moins de calcium.

Les différences de composition physicochimique et de structure des micelles de caséine des laits $\beta-C n A$ et $\beta-C n C$ ont une 
répercussion importante sur l'aptitude à la coagulation par la présure des 2 types de lait. Le temps de gélification des laits est très hautement discriminant au $\mathrm{pH}$ initial des laits. Les laits $\beta-C n C$ sont moins stables car ils sont plus acides. On sait en effet que l'acidification du lait provoque une dissolution du phosphate de calcium qui déstabilise les micelles de caséines en permettant la neutralisation des groupes chargés (Garnier, 1963). La gélification du lait se produit alors à un taux d'hydrolyse de la KCn plus faible (Pierre, 1983). L'abaissement du $\mathrm{pH}$ favorise également l'hydrolyse enzymatique de la $\mathrm{k}-\mathrm{Cn}$ par la chymosine enzyme dont le $\mathrm{pH}$ optimum d'activité est voisin de 5,5 - en modifiant la constante catalytique de l'équation de Michaelis-Menten modélisant la phase primaire de la coagulation par la présure (Brulé, 1991). À pH standardisé à 6,6 , il subsiste pourtant une différence significative dans les temps de gélification des 2 types de laits. Des facteurs explicatifs autres que le $\mathrm{pH}$ doivent donc être pris en considération. Plusieurs hypothèses peuvent être émises pour expliquer la moins bonne stabilité des micelles des laits $\beta-C n C$. La $\beta-C n C$ possède un caractère moins hydrophile du fait de la nonphosphorylation de la Ser 35 , ce qui diminue la charge de la micelle, et la gélification du lait a lieu à un taux d'hydrolyse de la $\kappa-\mathrm{Cn}$ plus faible, ce qu'ont montré Pearse et al (1986) en incorporant des caséines plus ou moins déphosphorylées dans des micelles artificielles. La $\beta$-Cn très labile joue un rôle majeur dans la phase d'agrégation des micelles de caséines (phase secondaire de la coagulation) or les laits $\beta-C n C$ sont plus riches en $\beta-C n$ que les laits $\beta-C n A$. Le degré de minéralisation des micelles de caséines au moment de leur déstabilisation n'est pas identique pour les laits des deux génotypes. Un lait peu minéralisé, tel que les laits $\beta-C n C$, pourrait avoir une coagulation plutôt de type lactique avec agrégation des sous-unités micellaires alors que le lait $\beta-C n$ A donnerait un coagulum présure par agrégation des micelles (Brulé, 1981). Les observations lors de la fabrication confirment que les caillés $\beta-C n C$ s'apparentent plus à un floculat qu'à un réseau protéique (fig 2). Dans ce cas, les temps de gélification mesurés pour les laits des 2 génotypes ne seraient pas comparables, la gélification des laits $\beta-C n C$ ne serait pas typique d'une coagulation par la présure. K20 et $A 30$ sont 2 paramètres discriminants des 2 génotypes au $\mathrm{pH}_{\mathrm{s}}$ mais pas au $\mathrm{pH}_{0}$ des laits. En effet, le $\mathrm{pH}_{0}$ plus élevé des laits $\beta$-Cn A entraîne un moindre affaiblissement des liaisons phosphocalciques et diminue la solubilité du calcium et du phosphate minéral de la micelle ce qui conduit à une réduction de la constante de vitesse de l'organisation du coagulum (Brulé, 1991) et donc à un accroissement du temps nécessaire pour obtenir une fermeté donnée (K20). De ce fait, 30 min après l'emprésurage des laits $\beta-C n A$, la fermeté maximale ne serait pas atteinte, ce qui rend impropre la comparaison entre les valeurs $A 30$ mesurées pour les 2 types de lait au $\mathrm{pH}_{0}$. $\grave{A} \mathrm{pH}_{\text {s }}$, le K20 plus court pour les laits $\beta-\mathrm{Cn} A$ s'explique facilement par des teneurs supérieures en protéines et en caséine. Comme le démontrent Hossain (1976) et Garnot et al (1982), la teneur en caséine détermine de façon très directe l'allure du raffermissement du coagulum. Le diamètre beaucoup plus faible des micelles $\beta$-Cn $A$ accentue le phénomène puisque du faible diamètre associé à une quantité plus importante de protéines résulte un nombre de particules plus important. Le temps d'agrégation étant inversement proportionnel au nombre de particules (Brulé, 1991), le K20 est plus court avec les laits $\beta$ - $C n$ A. La fermeté maximale à $\mathrm{pH}_{\mathrm{s}}$ plus élevée pour les laits $\beta-\mathrm{Cn} A$ s'explique aussi par la teneur en protéines plus importante de ces mêmes laits et la plus grande densité du réseau protéique formé (Dalgleish, 1980), Les laits $\beta$-Cn A étant plus riches en calcium colloïdal, le réseau n'en est que mieux structuré. Lors de la coagulation, le calcium fixé sur les 
micelles est rapidement échangé avec celui de la phase soluble et contribue à la formation de liaisons phosphocalciques intermicellaires (et non plus intramicellaires). Les groupements phosphates des caséines, particulièrement ceux de la $\beta-\mathrm{Cn}$, contribuent également au développement de la fermeté du gel (Pearse et al, 1986), or les micelles des laits $\beta$-Cn $C$ sont moins riches en groupements phosphates. Les micelles $\beta-\mathrm{Cn} C$ ont aussi un diamètre moyen beaucoup plus grand que les micelles $\beta-C n A$. Les micelles de grande taille ayant un rapport surface/volume proportionnellement plus faible, les liaisons potentielles entre micelles sont moins nombreuses et le coagulum est plus mou (Niki et Arima, 1984 ; Ford et Grandison, 1986). De plus, nos résultats confirment la tendance des laits contenant des micelles de fort diamètre à former des caillés mous en raison d'une répartition très hétérogène des tailles de micelles (Niki et Arima, 1984).

Les seules différences importantes de composition entre fromages, fabriqués avec les laits des 2 génotypes $\beta-C n$, portent sur la teneur en $M G$ et le $G / S$ des minifromages. Ces observations ne peuvent s'expliquer que par une mauvaise rétention de la $M G$ dans les caillés $\beta-C n C$ liée à un réseau protéique trop hétérogène et peu minéralisé.

Après 8 semaines d'affinage, la valeur moyenne des $\mathrm{pH}$ des minifromages expérimentaux $(5,4)$ est inférieure aux valeurs normales de $\mathrm{pH}$ d'un fromage de Beaufort affiné $(5,5$ à 5,8 ; Chamba et $a l, 1994)$. Le temps d'affinage fixé pour les minifromages à pâte cuite ne suffit donc pas pour atteindre parfaitement le stade de fin de maturation des fromages de Beaufort. Les paramètres (MG, G/S) qui discriminent bien les 2 types de laits ( $\beta-C n A$ et $\beta-C n C)$ sont aussi ceux qui différent le plus entre les minifromages expérimentaux et les fromages de Beaufort. Ces différences s'expliquent par la pauvreté en MG des laits individuels $\beta-C n C$
( $36 \mathrm{~g} / \mathrm{kg}$ en moyenne), et la standardisation des laits individuels en MG, mais aussi par l'accroissement des pertes de MG pour les minifabrications par rapport à des fabrications standards mettant en jeu de grands volumes de laits de mélange (Kerjean et al, 1987). À 8 semaines, le G/S ( 36 et $43 \%$ ) et P'ES (58 et $60 \%$ ) des minifromages sont inférieurs aux normales pour des fromages de Beaufort affinés (respectivement 49 à $51 \%$ et 62 à $64 \%$; Chamba et al, 1994). Cependant, si l'on analyse l'ESFD, on occulte les différences de teneur en MG liées au génotype de la $\beta-C n$ et la valeur moyenne de I'ESFD pour les minifromages ( $46 \%$ ) est très voisine de la valeur normale pour des fromages de Beaufort ( $45,6 \%$ ). Les teneurs en sel des minifromages $(1,3$ et $1,5 \mathrm{~g} / 100 \mathrm{~g}$ de fromage) sont en revanche un peu plus élevées qu'en fabrication de fromage de Beaufort $(0,8$ à $1,3 \mathrm{~g} / 100 \mathrm{~g}$ fromage ; Chamba et al, 1994). Un temps de saumurage de $3 \mathrm{~h}$ pour les minifromages était trop important pour obtenir un taux de sel correspondant à celui rencontré en fabrication de fromage de Beaufort. De plus, les minifromages étant plus humides, ils ont eu tendance à absorber plus de sel. II résulte toutefois, de l'ensemble de nos observations, que les caractéristiques globales du minifromage, mis à part sa teneur en $M G$, s'apparentent bien à celles d'une pâte cuite pressée type beaufort.

\section{CONCLUSION}

La moins bonne aptitude à la coagulation des laits $\beta$-Cn $C$ se traduit par l'obtention de gels mous peu minéralisés entraînant des pertes élevées de fines et de MG dans le lactosérum avec diminution des rendements fromagers et du gras/sec des fromages.

Les pertes relativement fortes de matière grasse observées en cuve par les fromagers du Beaufortin (en moyenne : 5 à $6 \mathrm{~g} / \mathrm{l}$ pour le Beaufort contre $3 \mathrm{~g} / \mathrm{l}$ pour l'emmen- 
tal) pourraient s'expliquer, outre par le travail d'un lait entier en cuve de fabrication, par la présence de ce variant $\mathrm{C}$ à une fréquence de $17 \%$, dans la population de vaches tarentaises.

\section{REMERCIEMENTS}

Ce travail a reçu une aide financière du GIS Alpes-du-Nord. Nous remercions A Hauwuy (SUACl Alpes-du-Nord, 73000 Chambéry) qui a organisé et supervisé la collecte des laits de Savoie. Nous tenons également à remercier $\mathrm{G}$ Pitel (INRA de Jouy-en-Josas) pour les fabrications fromagères, F Remeuf (INA Grignon, 78850) pour avoir mis à notre disposition dans son laboratoire l'appareillage nécessaire au dosage du calcium du lait et à la détermination de la taille des micelles de caséines, ainsi que $L$ Vassal (INRA de Jouy-en-Josas) pour sa relecture critique du manuscrit.

\section{RÉFÉRENCES}

AFNOR (1971) Lait. Détermination de la teneur en matière grasse. Méthode acidobulyrométrique. Norme NF V04-210

Alais C (1984) Science du lait, $4^{\circ}$ edn, Sepaic, Paris

Berdagué JL, Grappin R (1988) Affinage et qualité du Gruyère de Comté. VI-Caractéristiques sensorielles des fromages. Lait 68, 189-204

Brulé G (1981) Les minéraux. Rev Lait Fr 400, 61-65

Brulé G (1991) Caractéristiques physico-chimiques des protéines du lait. Aptitude à la coagulation, In: Colloque: Qualité des laits à la production et aptitude fromagère. Journées Lait, Rennes, 23-24 janvier

Brulé G, Lenoir J (1987) La coagulation du lait. In: Le Fromage (Eck A, ed). Lavoisier, Paris

Brulé G, Maubois JL, Fauquant J (1974) Étude de la teneur en éléments minéraux des produits obtenus lors de l'ultrafiltration du lait sur membrane. Lait 54 , 600-615

Casey M, Gruskovnjak J, Furst M (1986) Die Bedeutung von Plasmin bei der Reifung von Greyerzerkăse. Schweiz Milchw Forschung 16, 21-24

Chamba JF, Delacroix-Buchet A, Berdagué JL, Clément JF (1994) Une approche globale de la caractérisation des fromages. L'exemple du beaufort. Sci Aliments (à paraître)
Collin JC, Berdagué JL, Dognin-Bergeret M, Grappin R. (1987) Affinage et qualité du Gruyère de Comté. IV. Étude de la protéolyse. Lait 67, 299-318

Dalgleish DG (1980) Effect of milk concentration on rennet coagulation time. J Dairy Res 47, 231-235

Davies DT, Law AJR (1983) Variation in the protein composition of bovine casein micelles and serum casein in relation to micellar size and milk temperature. J Dairy Res 50, 67-75

Delacroix-Buchet A, Foumier S (1992) Protéolyse et texture des fromages à pâte cuite pressée. II. Influence de la chymosine et des conditions de fabrication. Lait 72, 53-72

Delacroix-Buchet A, Lefier D, Nuyts-Petit V (1993) Polymorphisme de la caséine $\kappa$ de 3 races bovines françaises et aptitude à la coagulation. Lait 73, 61-72

Dickson IR, Perkins DJ (1971) Studies on the interactions between purified bovine caseins and alkaline earth metal ions. Biochem J 124, 235-240

Donnelly WJ, Mc Neill GP, Buchheim W, Mc Gann TCA (1984) A comprehensive study of the relationship between size and protein composition in natural bovine casein micelles. Biochim Biophys Acta 789, 136-143

Farkye NY, Fox PF (1990) Observations on plasmin activity in cheese. J Dairy Res $57,413-418$

FIL (1967) Détermination de la teneur en phosphore du lait. Norme 42

FIL (1970) Méthode normalisée pour le dénombrement des germes totaux dans les poudres de lait et de lactosérum, méthode de référence. Norme 49

FIL (1972) Fromage. Détermination de la teneur en chlorures, méthode de référence. Norme 17A

FIL (1982) Fromages et fromages fondus. Détermination de l'extrait sec total, méthode de référence. Norme $4 \mathrm{~A}$

Ford GD, Grandison AS (1986) Effect of size of casein micelles on coagulation properties of skim milk. J Dairy Res 53, 129-133

Garnier J (1963) Kinetic study of a limited proteolysis: action of rennin on k-casein. Biochim Biophys Acta 66, 366-377

Garnot P, Rank TC, Olson NF (1982) Influence of protein and fat content of ultrafiltered milk on rheological properties of gels formed by chymosin. J Dairy Sci 65, 2267-2273

Grappin R, Jeunet R (1971) Essais de l'appareil "Compteur Coulter" utilisé pour la détermination du nombre de cellules totales des laits de troupeaux. Lait 51 , 273-293

Gripon JC, Desmazeaud MJ, Le Bars D, Bergère JL (1975) Étude du rôle des micro-organismes et des enzymes au cours de la maturation des fromages. II. Influence de la présure commerciale. Lait 55 , $502 \cdot 513$ 
Grosclaude $F$ (1988) Le polymorphisme génétique des principales lactoprotéines bovines. INRA Prod Anim 1, 5-17

Heiss E (1961) Essai de dosage de la matière grasse dans le fromage par des méthodes rapides. Dtsch Molk Ztg 82, 67-70

Holt C, Muir DD (1978) Natural variations in the average size of bovine casein micelles. II- Milk samples from creamery bulk silos in south west Scotland. J Dairy Res 45, 347-353

Hossain MA (1976) Der Einfluss des Protein fractionen auf das Gerrinnungs erhalten der Milch und die Festigkeit des Gallerte. Kiel Milchwirtsch Forschungsber 28, 43-58

Ichilczyk-Leone J, Amram Y, Schneid N, Lenoir J (1981) Le refroidissement du lait et son comportement en fromagerie. Rev Lait Fr 401, 7-14

Kerjean JR, Buisson V, Courroye M (1987) Miniaturisation de la fabrication fromagère. Tech Lait Market $1024,17-23$

Lenoir J (1985) Les caséines du lait. Rev Lait Fr 440, 17-23

Lin SHC, Dewan RK, Bloomfield VA, Morr CV (1971) Inelastic light-scattering study of the size distribution of bovine milk casein micelles. Biochemistry 10 , 4788-4793

Matheson AR (1981) The immunochemical determination of chymosin activity in cheese. N Z J Dairy Sci Technol 15, 33-41

Maubois JL, Mocquot G (1967) Comment ramener à la même teneur en substance sèche des fabrications de fromage en vue de comparer les rendements respectifs du lait en fromage. Rev Lait Fr 239, 15-18

Mietton B (1986) Les rendements en fromagerie. Éléments de méthodologie pour une meilleure détermination et utilisation des données. Rev ENIL 104, 6-16

Morini D, Losi G, Castagnetti GB, Benevelli M, Resmini $P$. Volonterio G (1975) L'influenza delle varianti genetiche della $\kappa$-caseina sulla dimensione delle micelle caseiniche. Sci Tec Latt-Casearia 26, 437-444

Niki R, Arima S (1984) Effects of size of casein micelle on firmness of rennet curd. Jpn J Zootech Sci 55, 409-415
Nuyts-Petit V (1991) Influence des variants génétiques des caséines bovines sur l'aptitude fromagère du lait de vaches de races traditionnelles. Thèse, Univ Compiègne

Olson NF (1990) The impact of lactic acid bacteria on cheese flavor. Fed Eur Microbiol Soc Microbiol Rev 87, 131-148

Papoff CM, Delacroix-Buchet A, Le Bars D, Campus RL, Vodret A (1994) Hydrolysis of bovine C $\beta$-casein by plasmin. It J Food Sci (soumis pour publication)

Pearse MJ, Linklater PM, Hall RJ, Mackinlay AG (1986) Effect of casein micelle composition and casein dephosphorylation on coagulation and syneresis. J Dairy Res 53, 381-390

Pien J (1976) Détermination du taux de matière grasse des fromages. Tech Lait 878, 15-17

Pierre A (1983) Influence de la modification de la charge des micelles de caséines sur le taux de caséinomacropeptide libéré par la présure au moment de la coagulation du lait. Lait 63, 217-229

Remeuf F, Lenoir J, Duby C (1989) Étude des relations entre les caractéristiques physico-chimiques des laits de chèvre et leur aptitude à la coagulation par la présure. Lait 69, 499-518

Ribadeau-Dumas B, Grappin R (1989) Milk protein analysis. Lait $69,357-416$

Rowland SJ (1938) The determination of the nitrogen distribution in milk. J Dairy Res 9, 42-46

Silverman GJ, Wolin AG, Kosikowski FV (1959) Simplification of standard methods for salt analysis in cheese. J Dairy Sci 42, 1095-1096

Uriel J (1966) Méthode d'électrophorèse dans des gels d'acrylamide-agarose. Bull Soc Chim Biol 48, 969982

Visser S (1993) Proteolytic enzymes and their relation to cheese ripening and flavor: an overview. J Dairy Sci 76, 329-350

Weinstein MJ, Doolittle RF (1972) Differential specificities of thrombin, plasmin and trypsin with regard to synthetic and natural substrates and inhibitors. Biochim Biophys Acta 258, 577-590 